\title{
What is the true incidence of renal artery stenosis after sympathetic denervation?
}

\author{
Yutang Wang ${ }^{1,2 *}$ \\ ${ }^{1}$ Queensland Research Centre for Peripheral Vascular Disease, School of Medicine and Dentistry, James Cook University, Townsville, QLD, Australia \\ 2 School of Health Sciences, Federation University Australia, Mount Helen, VIC, Australia \\ *Correspondence: yutangwang000@gmail.com
}

Edited by:

Clive May, University of Melbourne, Australia

Reviewed by:

Francesco Versaci, Cardiology Dept. Cardarelli Hospital - Campobasso - Italy, Italy

Keywords: clinical trials, renal artery stenosis, renal denervation, resistant hypertension, side effect

Renal denervation (RDN), a recently developed therapy for resistant hypertension, is generally regarded as a safe procedure (Krum et al., 2009; Esler et al., 2010; Bhatt et al., 2014). The Symplicity HTN trials reported that the rate of renal artery stenosis after RDN was low. For example, the Symplicity HTN-1 trial showed that 1 of $45(2.2 \%)$ denervated patients developed a non-obstructive renal artery stenosis in an untreated area at 6 months after RDN (Krum et al., 2009). This low rate of renal artery stenosis after RDN was confirmed by the 6-month report of the Symplicity HTN-2 trial $(N=106)$ (Esler et al., 2010) and the recently published 6-month report of the Symplicity HTN3 trial $(N=535)$ (Bhatt et al., 2014), which was 1.9 and $0.3 \%$, respectively. In these Symplicity HTN trials, renal artery stenosis occurred at a low rate $(0.3-2.2 \%)$ and was not reported to cause further complications.

However, some studies reported that renal artery stenosis occurred at a higher rate. For example, the EnligHTN I study (Worthley et al., 2013) reported that 2 of $46(4.3 \%)$ patients showed progression of a pre-existing renal artery stenosis; a study from 10 European expert centers (Persu et al., 2014) reported that 3 of $109(2.8 \%)$ patients showed progression of a non-significant $(<30 \%)$ renal artery stenosis; and Versaci et al. (2014a) reported that 2 of $11(18.2 \%)$ patients developed severe renal artery stenosis. It is worthwhile to point out that the sample size of 11 in Versaci et al.'s report is relatively small (Versaci et al., 2014a).
In 2012, Vonend et al. reported that a patient developed a $75 \%$ stenosis near the ostium of the right renal artery, which caused recurrent hypertension (Vonend et al., 2012). Subsequently, another 3 case reports reported that renal artery stenosis after RDN caused recurrent hypertension (Kaltenbach et al., 2012; Aguila et al., 2014; Pucci et al., 2014).

The causal role of RDN in promoting renal artery stenosis is currently speculative. However, given that (1) renal artery stenosis causes recurrent hypertension in denervated patients (Kaltenbach et al., 2012; Vonend et al., 2012; Aguila et al., 2014; Pucci et al., 2014) and (2) treatment of renal artery stenosis is not always safe and sometimes leads to death (Soriano-Perez et al., 2012), it is important to thoroughly investigate the effect of RDN on renal artery stenosis (Mahfoud and Kjeldsen, 2013; Wang, 2014a,b,c,d). To do this, the following three points need to be emphasized in future clinical trials on RDN:

(1) Long-term randomized trials are needed. Two major randomized trials on RDN, i.e., the Symplicity HTN-2 and HTN-3 trials (Esler et al., 2012; Kandzari et al., 2012), allowed patients in the randomized control group to receive RDN after completion of the 6-month study. This crossover design makes it difficult to investigate possible long-term side effects of RDN, e.g., promoting renal artery stenosis. Therefore, long-term randomized trials without a short-term crossover design are needed to investigate the effect of RDN on renal artery stenosis.

(2) Imaging methods monitoring renal artery stenosis need to be standardized. Symplicity HTN trials did not standardize renal artery imaging methods during follow ups. Ultrasonography, magnetic resonance angiography, and computerized tomographic angiography were used (Krum et al., 2009; Esler et al., 2010). The computerized tomographic angiography, the gold standard method to detect renal artery stenosis (Persu et al., 2012), was not the major imaging method in these trials. It is known that ultrasonography has limited visualization on renal artery stenosis because (1) the imaging is interfered by overlying adipose tissue and bowel gas (Zhang et al., 2009); and (2) the entire length of the renal artery or an accessory renal artery can be overlooked (Lao et al., 2011). Therefore, it is worthwhile to use computerized tomographic angiography as the standardized method during follow ups in future trials to investigate the effect of RDN on renal artery stenosis.

(3) It is likely that improved catheters for RDN using lower power radiofrequency over a shorter time will reduce the local tissue injury at the ablation site compared with that caused by the first generation RDN systems (Versaci et al., 2014b). However data regarding the vascular injury induced by these new devices are lacking. 


\section{ACKNOWLEDGMENT}

Yutang Wang is supported by the National Health and Medical Research Council (1062671).

\section{REFERENCES}

Aguila, F. J., Mediavilla Garcia, J. D., Navarro, E. M., Vargas Hitos, J. A., and Fernandez-Torres, C. (2014). Bilateral renal artery stenosis after renal denervation. Hypertension 63, e126-e127. doi: 10.1161/HYPERTENSIONAHA.113.03065

Bhatt, D. L., Kandzari, D. E., O'Neill, W. W., D’Agostino, R., Flack, J. M., Katzen, B. T., et al. (2014). A controlled trial of renal denervation for resistant hypertension. N. Engl. J. Med. 370, 1393-1401. doi: 10.1056/NEJMoa1402670

Esler, M. D., Krum, H., Schlaich, M., Schmieder, R. E., Bohm, M., and Sobotka, P. A. (2012). Renal sympathetic denervation for treatment of drug-resistant hypertension: one-year results from the Symplicity HTN-2 randomized, controlled trial. Circulation 126, 2976-2982. doi: 10.1161/CIRCULATIONAHA.112.130880

Esler, M. D., Krum, H., Sobotka, P. A., Schlaich, M. P., Schmieder, R. E., and Bohm, M. (2010). Renal sympathetic denervation in patients with treatment-resistant hypertension (The Symplicity HTN-2 Trial): a randomised controlled trial. Lancet 376, 1903-1909. doi: 10.1016/S0140-6736(10)62039-9

Kaltenbach, B., Id, D., Franke, J. C., Sievert, H., Hennersdorf, M., Maier, J., et al. (2012). Renal artery stenosis after renal sympathetic denervation. J. Am. Coll. Cardiol. 60, 2694-2695. doi: 10.1016/j.jacc.2012.09.027

Kandzari, D. E., Bhatt, D. L., Sobotka, P. A., O'Neill, W. W., Esler, M., Flack, J. M., et al. (2012). Catheter-based renal denervation for resistant hypertension: rationale and design of the SYMPLICITY HTN-3 Trial. Clin. Cardiol. 35, 528-535. doi: 10.1002/clc.22008

Krum, H., Schlaich, M., Whitbourn, R., Sobotka, P. A., Sadowski, J., Bartus, K., et al. (2009). Catheterbased renal sympathetic denervation for resistant hypertension: a multicentre safety and proof-ofprinciple cohort study. Lancet 373, 1275-1281. doi: 10.1016/S0140-6736(09)60566-3
Lao, D., Parasher, P. S., Cho, K. C., and Yeghiazarians, Y. (2011). Atherosclerotic renal artery stenosisdiagnosis and treatment. Mayo Clin. Proc. 86, 649-657. doi: 10.4065/mcp.2011.0181.

Mahfoud, F., and Kjeldsen, S. E. (2013). Catheter-based renal denervation: a word of caution. Eurointervention 8, 997-998. doi: 10.4244/EIJV8I9A152

Persu, A., Jin, Y., Azizi, M., Baelen, M., Volz, S., Elvan, A., et al. (2014). Blood pressure changes after renal denervation at 10 European expert centers. J. Hum. Hypertens. 28, 150-156. doi: 10.1038/jhh. 2013.88

Persu, A., Renkin, J., Thijs, L., and Staessen, J. A. (2012). Renal denervation: ultima ratio or standard in treatment-resistant hypertension. Hypertension 60, 596-606. doi: 10.1161/HYPERTENSIONAHA.112.195263

Pucci, G., Battista, F., Lazzari, L., Dominici, M., Boschetti, E., and Schillaci, G. (2014). Progression of renal artery stenosis after renal denervation. Circ. J. 78, 767-768. doi: 10.1253/circj.CJ13-0997

Soriano-Perez, A. M., Baca-Morilla, Y., Galindo-De Blas, B., Bejar-Palma, M. P., Martin-Ortiz, M., and Bueno-Millan, M. P. (2012). Renal artery rupture during complicated recovery from angioplasty to treat renal stenosis. Nefrologia 32 , 258-260. doi: 10.3265/Nefrologia.pre2011.Nov. 11174

Versaci, F., Trivisonno, A., Olivieri, C., Caranci, F., Brunese, L., and Prati, F. (2014a). Late renal artery stenosis after renal denervation: is it the tip of the iceberg? Int. J. Cardiol. 172, e507-e508. doi: 10.1016/j.ijcard.2014.01.018

Versaci, F., Trivisonno, A., Olivieri, C., Caranci, F., Brunese, L., and Prati, F. (2014b). Vascular response after percutaneous sympathectomy: not all devices are equal. Int. J. Cardiol. 174, 406-407. doi: 10.1016/j.ijcard.2014.04.049

Vonend, O., Antoch, G., Rump, L. C., and Blondin, D. (2012). Secondary rise in blood pressure after renal denervation. Lancet 380, 778. doi: 10.1016/S01406736(12)61145-3

Wang, Y. (2014a). It may be not suitable to perform renal denervation in renal arteries with significant stenosis. Int. J. Cardiol. 174, 750. doi: 10.1016/j.ijcard.2014.04.087
Wang, Y. (2014b). Limitations in current clinical trials on renal denervation. Int. J. Cardiol. 174, 225. doi: 10.1016/j.ijcard.2014.04.054

Wang, Y. (2014c). Patients with renal artery stenosis may not be suitable for renal denervation. Clin Res. Cardiol. 103, 585-586. doi: 10.1007/s00392014-0700-8

Wang, Y. (2014d). Renal artery stenosis may be responsible for the gradual return of high blood pressure after renal denervation. J. Clin. Hypertens. (Greenwich) 16, 313. doi: 10.1111/jch. 12265

Worthley, S. G., Tsioufis, C. P., Worthley, M. I. Sinhal, A., Chew, D. P., Meredith, I. T., et al. (2013). Safety and efficacy of a multi-electrode renal sympathetic denervation system in resistant hypertension: the EnligHTN I trial. Eur. Heart J. 34, 2132-2140. doi: 10.1093/eurheartj/ eht197

Zhang, H. L., Sos, T. A., Winchester, P. A., Gao, J., and Prince, M. R. (2009). Renal artery stenosis: imaging options, pitfalls, and concerns. Prog. Cardiovasc. Dis. 52, 209-219. doi: 10.1016/j.pcad.2009.10.003

Conflict of Interest Statement: The author declares that the research was conducted in the absence of any commercial or financial relationships that could be construed as a potential conflict of interest.

Received: 13 July 2014; paper pending published: 28 July 2014; accepted: 31 July 2014; published online: 15 August 2014.

Citation: Wang Y (2014) What is the true incidence of renal artery stenosis after sympathetic denervation? Front. Physiol. 5:311. doi: 10.3389/fphys.2014.00311

This article was submitted to Integrative Physiology, a section of the journal Frontiers in Physiology.

Copyright (c) 2014 Wang. This is an open-access article distributed under the terms of the Creative Commons Attribution License (CC BY). The use, distribution or reproduction in other forums is permitted, provided the original author(s) or licensor are credited and that the original publication in this journal is cited, in accordance with accepted academic practice. No use, distribution or reproduction is permitted which does not comply with these terms. 